University of Nebraska - Lincoln

DigitalCommons@University of Nebraska - Lincoln

Faculty Papers and Publications in Animal

Science

Animal Science Department

March 1996

\title{
Estimation of Variances Due to Direct and Maternal Effects for Growth Traits of Nelore Cattle
}

\author{
J. P. Eler \\ University of Nebraska-Lincoln \\ L. Dale Van Vleck \\ Roman L. Hruska U.S. Meat Animal Research Center, USDA-ARS, University of Nebraska-Lincoln, dvan- \\ vleck1@unl.edu \\ J. B. S. Ferraz \\ University of Nebraska-Lincoln \\ R. B. Lobo \\ Departamento de genetica, Faculdade de Medicina de Ribeirao Preto/USP. 14100-Ribeirao Preto (SP), \\ Brazil
}

Follow this and additional works at: https://digitalcommons.unl.edu/animalscifacpub

Part of the Animal Sciences Commons

Eler, J. P.; Van Vleck, L. Dale; Ferraz, J. B. S.; and Lobo, R. B., "Estimation of Variances Due to Direct and Maternal Effects for Growth Traits of Nelore Cattle" (1996). Faculty Papers and Publications in Animal Science. 103.

https://digitalcommons.unl.edu/animalscifacpub/103

This Article is brought to you for free and open access by the Animal Science Department at DigitalCommons@University of Nebraska - Lincoln. It has been accepted for inclusion in Faculty Papers and Publications in Animal Science by an authorized administrator of DigitalCommons@University of Nebraska - Lincoln. 


\title{
Estimation of Variances Due to Direct and Maternal Effects for Growth Traits of Nelore Cattle ${ }^{1,2}$
}

\author{
J. P. Eler*,3, L. D. Van Vleck', J B.S. Ferraz*, and R. B. Lôboł \\ *Department of Animal Science, University of Nebraska, Lincoln 68583-0908; \\ thoman L. Hruska U.S. Meat Animal Research Center, ARS, USDA, \\ University of Nebraska, Lincoln 68583-0908; \\ and ҒDepartamento de genética, Faculdade de Medicina de Ribeirão Preto/USP. \\ 14100-Ribeirão Preto (SP), Brazil
}

\begin{abstract}
Estimates of (co)variance components and genetic parameters were obtained for birth, 205-d, and 365-d weight for Nelore cattle in Brazil, using single and multiple-trait animal models. Data were from the Brazilian Zebu Breeders Association (ABCZ). Records of 27,549 calves sired by 587 bulls and raised on pasture in 57 herds were analyzed by restricted maximum likelihood fitting an animal model including direct and maternal genetic and permanent environmental effects. Single and multiple-trait analyses were carried out. Heritability estimates for direct effects were lower than previous values reported for the Nel ore breed. The estimates for
\end{abstract}

maternal genetic effects showed that the contribution of this component to the phenotypic variance of birth and weaning weight is not very high but is still present at yearling weight. Correlations between direct and maternal additive genetic effects were negative for all traits analyzed except for yearling weight in the single-trait analysis where the sign was positive but the magnitude was small (+.09). Genetic correlations between weaning and yearling weights were .74 (direct effect) and .84 (maternal effect). Permanent environmental and residual correlations among traits were also obtained.

Key Words: Beef Cattle, Maternal Effects, Genetic Parameters, Correlation

\section{Introduction}

The Nelore breed accounts for $70 \%$ of the registered zebu ( Bos indicus) cattle in Brazil. The breed exhibits large differences in growth potential among regions and even large differences between the two distinct production systems (bull breeding and commercial herds). This variability represents potential for genetic improvement for growth. The main features of the breed are its adaptability to tropical conditions and high fertility.

Although maintaining reproductive efficiency in the herd should be of particular concern, increasing

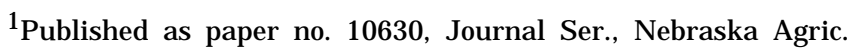
Res. Div., Univ. of Nebraska, Lincoln 68583-0908.

${ }^{2}$ The senior author wishes to acknowledge financial support of Conselho Nacional de Desenvolvimento Científico e Tecnológico (CNPq), Brazil. Appreciation is extended to Antonio Message J unior for his help in the data editing.

${ }^{3}$ Present address: Depto. de Ciências Básicas, Faculdade de Zootecnia e Engenharia de Alimentos, Universidade de São Paulo. 13630 - Pirassununga (SP), Brazil.

Received February 17, 1994.

Accepted May 19, 1995.
}

growth potential is very important to meat output from the production system. Planning appropriate breeding programs requires knowledge of genetic parameters and, for early growth traits of beef cattle, the joint effect of genes for growth potential and for maternal ability (Koch, 1972; Baker, 1980).

Based on the procedure presented by Willham (1963, 1972), Eler et al. (1989, 1992) obtained estimates of variance components and genetic parameters for Nelore cattle in Brazil. They found negative genetic correlations between direct and maternal additive genetic effects for growth traits until yearling weight. If such an antagonism exists, both direct and maternal components should be taken into account to achieve optimum genetic progress (see Baker, 1980 and Robison, 1981 for reviews). Van Vleck (1970) developed a selection index to account for these two components.

The negative estimates of genetic correlations for the Nelore population reported in previous studies needs further study. According to F oulley and Lefort (1978), procedures such as presented by Willham (1963) combine information in a non-optimal way, mainly because they ignore the fact that the same animal may contribute to several covariances. 
Conversely, maximum likelihood procedures are known to combine information in an optimal way (Harville, 1977), and restricted maximum likelihood (Patterson and Thompson, 1978) has become the method of choice to estimate variance components from field data (e.g., Boldman and Van Vleck, 1991; Meyer, 1992).

Increased computing power has recently allowed the use of restricted maximum likelihood (REML) with animal models to estimate variance components (e.g. Meyer, 1989; Boldman et al., 1991, 1993). The objective of this study was to estimate variance and covariance components due to direct and maternal genetic effects and permanent environmental effects for growth traits using REML procedures under single and multiple-trait animal models with data from Nelore cattle raised on pasture in the State of São Paulo, Brazil.

\section{Materials and Methods}

Data were obtained from the Brazilian Zebu Breeders Association (ABCZ). Records of 27,549 calves sired by 587 bulls and raised in 57 herds were analyzed. Three traits were considered: birth (BWT), weaning ( $\mathbf{W W}$ ), and yearling ( $\mathbf{Y W}$ ) weights. The calves were born from 1975 to 1984.

For birth and weaning weights the number of males and females were approximately the same. For yearling weight the total number of records was reduced to 16,747 and about $60 \%$ were females. The records were adjusted for the age of calf, according to a linear function, as described by Lasley (1978).

For single-trait analyses the complete data set was used but for the multiple-trait analysis the data were split into four samples to make the analysis computationally possible. A description of the samples is presented in Table 1. Averages of the four sets of estimates were assumed to represent variance components for the complete data set. Yerex (1988) has shown with simulation that simple averaging of REML estimates when samples are similar gives essentially the same result as the more difficult method of weighing by inverses of sampling variances.

\section{The Models}

The single-trait animal model for this analysis can be represented as follows:

$$
y=X \beta+Z g+M m+W p+e
$$

where $\mathbf{y}$ is a $N \times 1$ vector of records, $\beta$ denotes the vector of fixed effects (herd-year-season, sex, dam age class), $\mathbf{X}$ is the matrix that associates $\beta$ with $\mathbf{y} ; \mathbf{g}$ is the vector of breeding values for direct genetic effects, $\mathbf{Z}$ is the matrix that associates $\mathbf{g}$ with $\mathbf{y} ; \mathbf{m}$ is the vector of breeding values for maternal genetic effects,
$\mathbf{M}$ is the matrix that associates $\mathbf{m}$ with $\mathbf{y} ; \mathbf{p}$ is the vector of permanent environmental plus nonadditive genetic effects contributed by dams to records of their progeny, $\mathbf{W}$ is the matrix that associates $\mathbf{p}$ with $\mathbf{y}$; and $\mathbf{e}$ is the vector of residual effects, peculiar to observations, that are not explained by other parts of the model.

For this model:

$$
\begin{gathered}
\mathbf{E}[\mathbf{y}]=\mathbf{X} \boldsymbol{\beta} \\
\operatorname{Var}\left[\begin{array}{l}
\mathbf{g} \\
\mathbf{m} \\
\mathbf{p} \\
\mathbf{e}
\end{array}\right]=\left[\begin{array}{llll}
\mathbf{A} \boldsymbol{\sigma}_{\mathrm{g}}^{2} & \mathbf{A} \boldsymbol{\sigma}_{\mathrm{gm}} & 0 & 0 \\
\mathbf{A} \boldsymbol{\sigma}_{\mathrm{gm}} & \mathbf{A} \boldsymbol{\sigma}_{\mathrm{m}}^{2} & 0 & 0 \\
0 & 0 & \mathbf{I}_{\mathrm{C}} \boldsymbol{\sigma}_{\mathrm{p}}^{2} & 0 \\
0 & 0 & 0 & \mathbf{I}_{\mathrm{N}} \boldsymbol{\sigma}_{\mathrm{e}}^{2}
\end{array}\right]
\end{gathered}
$$

where $\mathrm{c}$ is number of cows and $\mathrm{N}$ is number of records, $\mathbf{A}$ is the numerator relationship matrix and the $\mathbf{I}$ are identity matrices of appropriate order. In setting up the mixed-model equations (Henderson, 1973, 1975) $\mathbf{Z}, \mathbf{M}$, and $\mathbf{A}$ are augmented to include animals without records that contribute to relationships.

For the three traits used for a combined analysis, the multiple-trait animal model can be represented as follows:

$$
\begin{aligned}
& {\left[\begin{array}{l}
\mathbf{y}_{1} \\
\mathbf{y}_{2} \\
\mathbf{y}_{3}
\end{array}\right]=\left[\begin{array}{lll}
\mathbf{X}_{1} & 0 & 0 \\
0 & \mathbf{X}_{2} & 0 \\
0 & 0 & \mathbf{X}_{3}
\end{array}\right]\left[\begin{array}{l}
\beta_{1} \\
\boldsymbol{\beta}_{2} \\
\beta_{3}
\end{array}\right]+\left[\begin{array}{lll}
\mathbf{Z}_{1} & 0 & 0 \\
0 & \mathbf{Z}_{2} & 0 \\
0 & 0 & \mathbf{Z}_{3}
\end{array}\right]\left[\begin{array}{l}
\mathbf{g}_{1} \\
\mathbf{g}_{2} \\
\mathbf{g}_{3}
\end{array}\right]+} \\
& {\left[\begin{array}{lll}
\mathbf{M}_{1} & 0 & 0 \\
0 & \mathbf{M}_{2} & 0 \\
0 & 0 & \mathbf{M}_{3}
\end{array}\right]\left[\begin{array}{l}
\mathbf{m}_{1} \\
\mathbf{m}_{2} \\
\mathbf{m}_{3}
\end{array}\right]\left[\begin{array}{lll}
\mathbf{W}_{1} & 0 & 0 \\
0 & \mathbf{W}_{2} & 0 \\
0 & 0 & \mathbf{W}_{3}
\end{array}\right]\left[\begin{array}{l}
\mathbf{p}_{1} \\
\mathbf{p}_{2} \\
\mathbf{p}_{3}
\end{array}\right]+\left[\begin{array}{l}
\mathbf{e}_{1} \\
\mathbf{e}_{2} \\
\mathbf{e}_{3}
\end{array}\right]}
\end{aligned}
$$

where the subscripts 1,2 , and 3 represent birth, weaning, and yearling weights, respectively. As be fore, for this model,

$$
\mathbf{E}\left[\begin{array}{l}
\mathbf{y}_{1} \\
\mathbf{y}_{2} \\
\mathbf{y}_{3}
\end{array}\right]=\left[\begin{array}{lll}
\mathbf{X}_{1} & 0 & 0 \\
0 & \mathbf{X}_{2} & 0 \\
0 & 0 & \mathbf{X}_{3}
\end{array}\right]\left[\begin{array}{l}
\beta_{1} \\
\beta_{2} \\
\beta_{3}
\end{array}\right]
$$

and the variance-covariance matrix for genetic effects is $\mathbf{G}=\mathbf{G}_{0} \otimes \mathbf{A}$ where

$$
\mathbf{G}_{0}=\left[\begin{array}{llllll}
\boldsymbol{\sigma}_{\mathrm{g} 1}^{2} & \sigma_{\mathrm{g} 12} & \sigma_{\mathrm{g} 13} & \sigma_{\mathrm{gm} 1} & 0 & 0 \\
\sigma_{\mathrm{g} 12} & \sigma_{\mathrm{g} 2}^{2} & \sigma_{\mathrm{g} 23} & 0 & \sigma_{\mathrm{gm} 2} & 0 \\
\sigma_{\mathrm{g} 13} & \sigma_{\mathrm{g} 23} & \sigma_{\mathrm{g} 3}^{2} & 0 & 0 & \sigma_{\mathrm{gm} 3}^{2} \\
\sigma_{\mathrm{gm} 1} & 0 & 0 & \sigma_{\mathrm{m} 12} & \sigma_{\mathrm{m} 13} \\
0 & \sigma_{\mathrm{gm} 2} & 0 & \sigma_{\mathrm{m} 12} & \sigma_{\mathrm{m} 2}^{2} & \sigma_{\mathrm{m} 23} \\
0 & 0 & \sigma_{\mathrm{gm} 3} & \sigma_{\mathrm{m} 13} & \sigma_{\mathrm{m} 23} & \sigma_{\mathrm{m} 3}^{2}
\end{array}\right]
$$

As shown in $\mathbf{G}_{0}$, the genetic effect for one trait and genetic maternal effect for any other trait was assumed to be uncorrelated in order to decrease computing time for the other 27 components. The 
Table 1. Characteristics of the samples for multivariate analyses ${ }^{\mathrm{a}}$

\begin{tabular}{|c|c|c|c|c|c|c|c|c|c|c|c|c|}
\hline \multirow[b]{2}{*}{ Samples } & \multirow[b]{2}{*}{ Records $^{b}$} & \multirow[b]{2}{*}{ Herds } & \multirow[b]{2}{*}{ Sires } & \multicolumn{3}{|c|}{ BWT, kg } & \multicolumn{3}{|c|}{ WW, kg } & \multicolumn{3}{|c|}{$\mathrm{YW}, \mathrm{kg}$} \\
\hline & & & & Avg & SD & CV & Avg & SD & $\mathrm{CV}$ & Avg & SD & $\mathrm{CV}$ \\
\hline 1 & $\begin{array}{r}6,780 \\
(4,831) \\
6,911\end{array}$ & 14 & 205 & 29.4 & 3.2 & 10.9 & 155.7 & 23.5 & 15.1 & 215.5 & 43.6 & 20.2 \\
\hline 2 & $\begin{array}{r}(4,044) \\
7,170\end{array}$ & 15 & 211 & 28.5 & 2.4 & 8.3 & 151.8 & 24.3 & 16.0 & 205.8 & 35.1 & 17.0 \\
\hline 3 & $\begin{array}{r}(4,486) \\
6,688\end{array}$ & 14 & 210 & 28.9 & 2.1 & 7.2 & 157.2 & 23.6 & 15.0 & 213.5 & 35.8 & 16.8 \\
\hline 4 & $(3,386)$ & 14 & 194 & 28.6 & 2.2 & 7.7 & 154.4 & 25.6 & 16.4 & 212.5 & 38.5 & 18.1 \\
\hline Total & $\begin{array}{c}27,549 \\
(16,747)\end{array}$ & 57 & 587 & 28.8 & 2.5 & 8.6 & 155.0 & 24.3 & 15.7 & 212.0 & 38.8 & 18.3 \\
\hline
\end{tabular}

${ }^{\mathrm{a}} \mathrm{BWT}=$ birth weight, $\mathrm{WW}=$ weaning weight, $\mathrm{YW}=$ yearling weight.

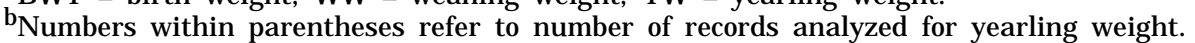

variance-covariance matrix for permanent environmental effects is as follows:

$$
\mathbf{P}=\mathbf{P}_{0} \otimes \mathbf{I}_{\mathrm{C}}
$$

where

$$
\mathbf{P}_{0}=\left[\begin{array}{lll}
\boldsymbol{\sigma}_{\mathrm{p} 1}^{2} & \boldsymbol{\sigma}_{\mathrm{p} 12} & \boldsymbol{\sigma}_{\mathrm{p} 13} \\
\boldsymbol{\sigma}_{\mathrm{p} 12} & \boldsymbol{\sigma}_{\mathrm{p} 2}^{2} & \boldsymbol{\sigma}_{\mathrm{p} 23} \\
\boldsymbol{\sigma}_{\mathrm{p} 13} & \boldsymbol{\sigma}_{\mathrm{p} 23} & \boldsymbol{\sigma}_{\mathrm{p} 3}^{2}
\end{array}\right]
$$

The variance-covariance matrix for residual effects, $\mathbf{R}$, is block diagonal with each block one of seven residual covariance matrices corresponding to which set of one, two, or three traits is measured on each animal.

Estimation of Variance and

Covariance Components

Variance and covariance components were estimated by restricted maximum likelihood (REML) using a derivative-free algorithm (Smith and Graser, 1986). The procedure is the same as that described by Núñez-Dominguez et al. (1993). The multiple-trait DFREML program was developed by Boldman et al. (1991, 1993).

\section{RESULTS AND DISCUSSION}

\section{Genetic Parameters}

Estimates of (co)variance components and genetic parameters for birth, weaning and yearling weights are shown in Tables 2 (single-trait) and 3 (multipletrait analysis). The values presented as multiple-trait estimates in Table 3 are averages of variance component estimates for multiple-trait analyses of the four samples. "Empirical" standard errors, as presented by Dimov et al. (1995), were computed from the sample estimates.
For the three traits analyzed, the estimates of heritability for additive genetic effects $\left(h^{2}\right)$ in both single-trait and multiple-trait analyses were smaller than previous values reported in the literature for the Nelore breed from different states in Brazil (Figueiredo et al., 1978; Milagres et al., 1985; Nobre et al., 1985; Rosa et al., 1986). The previous estimates used a nested model with sires nested within herds, ignoring maternal effects. Meyer (1992) showed that models not accounting for maternal effects could yield substantially higher estimates of additive direct genetic variance and, therefore, higher estimates of

Table 2. Estimates of variance components $\left(\mathrm{kg}^{2}\right)$ and genetic parameters from univariate analysis of birth weight (BWT), weaning weight (WW), and yearling weight (YW)

\begin{tabular}{lcrr}
\hline \hline Item & BWT & WW & YW \\
\hline Variance components $^{\mathrm{a}}$ & & & \\
$\sigma^{2} \mathrm{~g}$ & .92 & 47.37 & 121.28 \\
$\sigma_{\mathrm{m}}^{2}$ & .5 & 46.38 & 75.45 \\
$\sigma_{\mathrm{gm}}$ & -.49 & -15.07 & 8.18 \\
$\sigma_{\mathrm{p}}^{2}$ & .3 & 48.85 & 14.39 \\
$\sigma^{2} \mathrm{e}$ & 3.01 & 227.53 & 550.49 \\
$\sigma_{\mathrm{t}}^{2}$ & 4.23 & 355.06 & 769.79 \\
Genetic parameters $^{\mathrm{b}}$ & & & \\
$\mathrm{h}^{2} \mathrm{~g}$ & .22 & .13 & .16 \\
$\mathrm{~h}^{2} \mathrm{~m}$ & .12 & .13 & .10 \\
$\mathrm{r}_{\mathrm{gm}}$ & -.72 & -.32 & .09 \\
$\mathrm{~h}^{2} \mathrm{t}$ & .1 & .14 & .22 \\
$\mathrm{c}^{2}$ & .07 & .14 & .02 \\
$\mathrm{e}^{2}$ & .71 & .64 & .72 \\
\hline
\end{tabular}

$\mathrm{a}_{\sigma^{2}} \mathrm{~g}=$ direct additive genetic variance, $\sigma_{\mathrm{m}}^{2}=$ maternal additive genetic variance, $\sigma_{\mathrm{gm}}=$ covariance between direct additive and maternal additive genetic effects, $\sigma^{2} \mathrm{p}=$ permanent environmental variance, $\sigma^{2} \mathrm{e}=$ environmental variance, and $\sigma_{\mathrm{t}}^{2}=$ phenotypic variance.

$\mathrm{b}^{2} \mathrm{~g}=$ direct additive heritability, $\mathrm{h}^{2} \mathrm{~m}=$ maternal additive heritability, $r_{\mathrm{gm}}=$ genetic correlation between direct additive and maternal additive effects, $h^{2}=$ total heritability, $c^{2}=$ fraction of variance due to permanent environmental effects, and $\mathrm{e}^{2}=$ fraction of variance due to temporary environmental effects. 
Table 3. Average (Avg) estimates \pm empirical standard error (SE) of variance components $\left(\mathrm{kg}^{2}\right)$ and genetic parameters from multivariate analyses of birth weight (BWT), weaning weight (WW), and yearling weight (YW)

\begin{tabular}{|c|c|c|c|c|c|}
\hline Item & BWT & \multicolumn{2}{|l|}{ WW } & \multicolumn{2}{|c|}{ YW } \\
\hline \multicolumn{6}{|c|}{ Variance components ${ }^{a}$} \\
\hline$\sigma_{g}^{2}$ & $1.08 \pm .35$ & $49.85 \pm$ & 9.92 & $128.14 \pm$ & 13.44 \\
\hline$\sigma_{\mathrm{m}}^{2^{y}}$ & $.29 \pm .12$ & $60.06 \pm$ & 8.26 & $83.58 \pm$ & 26.31 \\
\hline$\sigma_{\mathrm{gm}}$ & $-.17 \pm .09$ & $-5.89 \pm$ & 2.55 & $-21.38 \pm$ & 14.58 \\
\hline$\sigma^{2} \mathrm{p}$ & $.12 \pm .08$ & $18.48 \pm$ & 7.47 & $22.96 \pm$ & 15.47 \\
\hline$\sigma^{2}$ & $2.87 \pm 1.32$ & $232.54 \pm$ & 12.85 & $549.00 \pm$ & 69.02 \\
\hline$\sigma^{2}$ & $4.18 \pm 1.88$ & $355.04 \pm$ & 13.93 & $766.78 \pm$ & 58.79 \\
\hline \multicolumn{6}{|c|}{ Genetic parameters ${ }^{b}$} \\
\hline$h^{2} g$ & $.29 \pm .04$ & $.14 \pm$ & .02 & $.17 \pm$ & .03 \\
\hline $\mathrm{h}^{2_{m}^{9}}$ & $.08 \pm .04$ & $.17 \pm$ & .03 & $.12 \pm$ & .04 \\
\hline$r_{\mathrm{gm}}$ & $-.38 \pm .16$ & $-.13 \pm$ & .07 & $-.17 \pm$ & .09 \\
\hline$h^{2} t$ & $.23 \pm .02$ & $.20 \pm$ & .04 & $.18 \pm$ & .02 \\
\hline$c^{2}$ & $.03 \pm .01$ & $.05 \pm$ & .02 & $.04 \pm$ & .04 \\
\hline $\mathrm{e}^{2}$ & $.68 \pm .02$ & $.66 \pm$ & .04 & $.71 \pm$ & .04 \\
\hline
\end{tabular}

$\mathrm{h}^{2} \mathrm{~g}$. For models with sires nested within herds, the sire variance component also could be inflated by a sire $\times$ herd interaction (Tess et al., 1979). These reasons may explain, at least in part, the higher estimates of $h^{2} \mathrm{~g}$ previously reported for the Nelore breed. On the other hand, the average estimates for beef cattle ( Bos taurus) summarized by Meyer (1992) are higher $(.37, .25$ and .27$)$ than those estimated in this study for birth, weaning and yearling weights, respectively.

The contribution of maternal effects to the phenotypic variance $\left(\mathrm{h}^{2} \mathrm{~m}\right)$ is relatively high in all traits. For birth weight, the single-trait estimate (.12) and, for weaning and yearling weights, the multiple-trait estimates (.17 and .12), agree with previous reports by Eler et al. (1989), who analyzed the same data by the method proposed by Willham (1963). The averages of estimates summarized by Meyer (1992) are .16 (BWT), .19 (WW), and .07 (Y W). High estimates of $h^{2} \mathrm{~m}$ for yearling weight were unexpected because at this age the calves do not depend on their mother and the weight should reflect only the direct effect of the genes on growth except for carry over maternal effects from before weaning. Similar results, however, were found by Mackinnon et al. (1991) for Zebu crosses in Australia. For animals raised on pasture without any supplementary feeding, the length of time from weaning to yearling is probably not enough that compensatory gain could buffer completely the maternal effect existing at weaning. This point is of particular concern if selection is based on yearling weight. In order to clarify whether maternal effects are strictly carry-over effects, analysis on postweaning average daily gain (ADG) was performed. Heritability of both direct and maternal effects for ADG was lower than that for YW. However, for maternal effect the decrease was more accentuated. In the single-trait analysis $\mathrm{h}^{2} \mathrm{~m}$ dropped from .10 for $\mathrm{YW}$ to .03 for postweaning $A D G$, and in the multiple-trait analysis it dropped from .12 for $Y W$ to .08 for ADG. It seems that maternal effect is indeed small for postweaning ADG, although in multiple-trait analysis the genetic correlation with preweaning ADG makes it a little higher.

The correlation between direct and maternal effects $\left(r_{\mathrm{gm}}\right)$ was negative for birth and weaning weights, and the magnitude was less in the multiple-trait analysis. For yearling weight the sign for the estimates was different for single-trait (+.09) and multiple-trait ( -.17$)$ analyses. For this trait the number of records was approximately $50 \%$ less because farmers cull a number of calves at weaning, mainly males. This procedure may be selective. In other words, animals with low performance at weaning may not be weighed at yearling age. The multiple-trait analysis includes records on which any culling was based and so should account for selection on the correlated traits of birth and weaning weights on the estimation of variance components for yearling weight. In both analyses, however, the magnitude of the correlation $\left(r_{\mathrm{gm}}\right)$ is small and probably not very important from a biological point of view.

For birth and weaning weight, total heritability $\left(h^{2}{ }_{t}\right)$ estimated from multiple-trait analysis was higher than from singletrait analysis due to the lower magnitude of the negative covariance between direct and maternal effects $\left(\sigma_{\mathrm{gm}}\right)$ obtained from multipletrait analysis. For yearling weight, due to the negative 
estimate of $\sigma_{\mathrm{gm}}$ only from the multiple-trait analysis, the value of $\mathrm{h}_{\mathrm{t}}$ in the multiple-trait was less than from the single-trait analysis.

\section{Permanent Environmental and Residual Variances}

The permanent environmental effect is coded as an effect of the dam (e.g., possibly due to uterine capacity, feeding level in late gestation, and maternal behavior). Table 3 shows that the ratio of the permanent environmental variance to the phenotypic variance $\left(c^{2}\right)$ estimated for birth weight ranged from $3 \%$ (multiple-trait) to 7\% (single-trait). For weaning weight the estimated ratios were $5 \%$ (multiple-trait) to $14 \%$ (single-trait), and for yearling weight the range was from $4 \%$ (multiple-trait) to $2 \%$ (singletrait).

The postnatal permanent environmental effects in beef cattle are due to incidents that affect all records of progeny of the same cow. These effects could be due to a high level of feeding of heifers, leading to fat deposition into the udder glands (J ohnson and Morant, 1984) or, as is most likely in tropical areas, related to sequels of some disease. Accidents to the udder may also create permanent differences among cows. In these cases the expression of differences among cows would be in terms of milk output. From weaning until yearling age the calves do not depend on the cow's milk production, and the estimate of $c^{2}$ for yearling weight is probably due to effects on weaning weight. Estimates of $c^{2}$ for all the traits were well within the range of the literature estimates for beef cattle as summarized by Meyer (1992).

The residual variance estimates were large and similar for the three traits in both analyses. The ratio to the phenotypic variance $\left(\mathrm{e}^{2}\right)$ ranged from 64 to $72 \%$.

\section{Genetic and Environmental Correlations}

Among Traits

Estimates of genetic, phenotypic, and residual correlations among traits are shown in Table 4 and are means of the estimates for individual samples from which the "empirical" standard errors were computed. The additive direct and also the maternal genetic correlations between weaning and yearling weights were high, indicating that selection for one trait should result in genetic improvement in the other trait. The same correlations when involving birth weight were low. The same pattern was observed for phenotypic, permanent environmental, and residual correlations among traits. The estimates agree with previous estimates using Nelore data collected by the breed association (Milagres et al., 1985; Eler et al., 1989). This would mean that selection for weaning or yearling weights would not quickly result in increased birth weight. However, results from the literature summarized by Mohiuddin (1993) indicate that our estimates are lower than usual for Bos taurus, or even for Bos indicus. This subject deserves more investigation, and analyzing Nelore data from outside the breed association would be recommended.

Because the genetic and environmental correlations between weaning and yearling weight were not close to unity, it is not possible to conclude that the maternal effects on yearling weight are only a "carryover" of those effects, as suggested by Meyer et al. (1993) for beef cattle in Australia.

Table 4. Average covariances (above diagonal) and correlations (below diagonal) \pm empirical standard errors for birth weight (BWT), weaning weight (WW), and yearling weight (YW) from multivariate analyses

\begin{tabular}{|c|c|c|c|}
\hline Trait & BWT & WW & YW \\
\hline \multicolumn{4}{|c|}{ Direct additive genetic effects } \\
\hline BWT & - & $1.60 \pm .95$ & $2.22 \pm$ \\
\hline WW & $.23 \pm .13$ & - & $58.30 \pm 6.89$ \\
\hline YW & $.16 \pm .06$ & $.74 \pm .05$ & - \\
\hline \multicolumn{4}{|c|}{ Maternal additive genetic effects } \\
\hline BWT & - & $.62 \pm .52$ & $.64 \pm$ \\
\hline WW & $.21 \pm .15$ & - & $56.48 \pm$ \\
\hline YW & $.18 \pm .10$ & $.84 \pm .07$ & - \\
\hline \multicolumn{4}{|c|}{ Maternal permanent environmental effects } \\
\hline BWT & - & $.37 \pm .31$ & $.43 \pm .24$ \\
\hline WW & $.27 \pm .21$ & - & $17.56 \pm 11.21$ \\
\hline YW & $.45 \pm .25$ & $.80 \pm .17$ & - \\
\hline \multicolumn{4}{|c|}{ Residual effects } \\
\hline BWT & - & $3.79 \pm 1.60$ & $5.29 \pm 2.54$ \\
\hline WW & $.14 \pm .03$ & - & $230.19 \pm 19.35$ \\
\hline YW & $.12 \pm .03$ & $.64 \pm .01$ & - \\
\hline \multicolumn{4}{|c|}{ Phenotypic effect } \\
\hline BWT & - & $6.32 \pm 3.22$ & $8.58 \pm$ \\
\hline WW & $.15 \pm .05$ & - & $362.53 \pm$ \\
\hline YW & $.14 \pm .04$ & $.70 \pm .01$ & - \\
\hline
\end{tabular}




\section{Implications}

The low heritability estimates for direct genetic effects $\left(h^{2} g\right)$ suggest that progeny tests should be used in this population to increase genetic improvement. Due to the high contribution of maternal effects to the phenotypic variance of yearling weight, those effects should be taken into account in genetic evaluations for yearling weight. Because the genetic correlations between direct and maternal effects are negative for all traits analyzed, methods of selection accounting for both direct and maternal effects would result in greater economic response to long-term selection than selection based only on direct genetic effects.

\section{Literature Cited}

Baker, R. L. 1980. The role of maternal effects on the efficiency of selection in beef cattle-A review. Proc. N.Z. Soc. Anim. Prod. 40:285.

Boldman, K. G., L. A. Kriese, L. D. Van Vleck, and S. D. Kachman. 1993. A Manual for Use of MTDFREML-A Set of Programs to Obtain Estimates of Variances and Covariances. ARS, USDA, Washington, DC.

Boldman, K. G., and L. D. Van Vleck. 1991. Derivative-free restricted maximum likelihood estimation in animal model with a sparse matrix solver. J. Dairy Sci. 74:4337.

Dimov, G., L. G. Albuquerque, J . F. Keown, L. D. Van Vleck, and H. D. Norman. 1995. Variance of interaction effects of sire and herd for yield traits of Holsteins in California, New York, and Pennsylvania with an animal model. J. Dairy Sci. 78:939.

Eler, J. P., J.B.S. Ferraz, R. B. Lôbo, and L. A. J osakian. 1992. Genetic antagonism between growth and maternal ability in Nelore cattle. J. Anim. Sci. 70(Suppl. 1):138 (Abstr.).

Eler, J. P., R. B. Lôbo, and F.A.M. Duarte. 1989. Avaliação dos efeitos genéticos direto e materno em pesos de bovinos da raça Nelore, criados no Estado de São Paulo. Rev. Soc. Bras. Zootec. 18:112.

Figueiredo, G. R., M. A. Silva, J. C. Milagres, A. Ludwig, and A. N. Rosa. 1978. Estimativas de parâmetros genéticos e fenotípicos de pesos e ganhos de pesos de animais Nelore após a desmama. Rev. Soc. Bras. Zootec. 7:286.

Foulley, J . L., and G. Lefort. 1978. Méthodes d'estimation des effects directs et maternels en sélection animale. Ann. Genet. Sel. Anim. 10:475.

Harville, D. A. 1977. Maximum likelihood approaches to variance component estimation and to related problems. J. Am. Stat. Assoc. 72:330.

Henderson, C. R. 1973. Sire evaluation and genetic trends. In: Proc. Symposium in Honor of J ay L. Lush. Am. Soc. Anim. Sci., Champaign, IL.
Henderson, C. R. 1975. Best Linear Unbiased Prediction under a selection model. Biometrics 31:423.

Koch, R. M. 1972. The role of maternal effects in animal breeding: VI. Maternal effects in beef cattle. J. Anim. Sci. 35:1316.

Lasley, J. 1978. Genetics of Livestock improvement (3rd Ed.). pp 331-339. Prentice-Hall, Englewood Cliffs, NJ .

Mackinnon, M. J ., K. Meyer, and D.J .S. Hetzel. 1991. Genetic variation and covariation for growth, parasite resistance and heat tolerance in tropical cattle. Livest. Prod. Sci. 27:105.

Meyer, K. 1989. Restricted Maximum Likelihood to estimate variance components for animal models with several random effects using a derivative-free al gorithm. Genet. Sel. Evol. 21:317.

Meyer, K. 1992. Variance Components due to direct and maternal effects for growth traits of Australian beef cattle. Livest. Prod. Sci. 31:179.

Meyer, K., M. J. Carrick, and B.J .P. Donnelly. 1993. Genetic parameters for growth traits of Australian beef cattle from a multibreed selection experiment. J . Anim. Sci. 71:2614.

Milagres, J . C., L.O.C. Silva, P.R.C. Nobre, and A. N. Rosa. 1985 Influência de fatores de meio e herança sobre os pesos de animais da raca Nelore no Estado de Minas Gerais. Rev. Soc. Bras. Zootec. 14:463.

Mohiuddin, G. 1993. Estimates of genetic and phenotypic parameters of some performance traits in beef cattle. Anim. Breed. Abstr. 61(8):495.

Nobre, P.R.C., A. N. Rosa, and L.O.C. Silva. 1985. Influência de fatores genéticos e de meio sobre os pesos de gado Nelore no Estado da Bahia, Brasil. Rev. Soc. Bras. Zootec. 14:338.

Núñez-Dominguez, R., L. D. Van Vleck, K. G. Boldman, and L. V. Cundiff. 1993. Correlations for genetic expression for growth of calves of Hereford and Angus dams using a multivariate animal model. J. Anim. Sci. 71:2330.

Patterson, H. D., and R. Thompson. 1971. Recovery of inter-block information when block sizes are unequal. Biometrika 58:545.

Robison, O. W. 1981. The influence of maternal effects on the efficiency of selection-A review. Livest. Prod. Sci. 8:121.

Rosa, A. N., L.O.C. Silva, and P.R.C. Nobre. 1986. Avaliação do desempenho de animais Nelore em Controle de Desenvolvimento Ponderal no Estado do Mato Grosso do Sul. Rev. Soc. Bras. Zootec. 15:515.

Smith, S. P., and H.-U. Graser. 1986. Estimating variance components in a class of mixed models by restricted maximum likelihood. J. Dairy Sci. 69:1156.

Tess, M. W., D. D. Kress, P. S. Burfening, and R. L. Friedrich. 1979. Sire by environment interactions in Simmental-sired calves. J . Anim. Sci. 49:964.

Van Vleck, L. D. 1970. Index Selection for Direct and Maternal Genetic Components of Economic Traits. Biometrics 26:477.

Willham, R. L. 1963. The covariance between relatives for characters composed of components contributed by related individuals. Biometrics 19:18.

Willham, R. L. 1972. The role of maternal effects in animal breeding: III. Biometrical aspects of maternal effects in animals. J . Anim. Sci. 35:1288.

Yerex, R. P. 1988. Pooling restricted maximum likelihood estimates from data sets under the animal model. PhD. Dissertation. Cornell Univ., Ithaca, NY. 